\title{
KAJIAN TANAMAN PENYERAP TIMBAL (Pb) DAN PENGIKAT KARBON DI LINGKUNGAN KAMPUS UNIVERSITAS JAMBI
}

\section{STUDY ON PLANT ABSORB LEAD (Pb) AND CARBON IN ENVIRONMENT CAMPUS UNIVERSITY OF JAMBI}

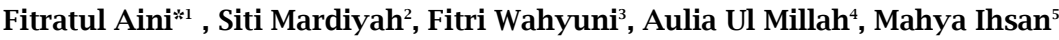 \\ ${ }^{12345}$ Program Studi Biologi, Fakultas Sains dan Teknologi, Universitas Jambi \\ E-mail : *fitratulaini47@gmail.com
}

\begin{abstract}
The University of Jambi (UNJA) in Mendalo has the highest number of students compared to other UNJA campuses, and most students use motor vehicles. The campus is also located on the Sumatra highway through which many smoke-generating vehicles affect air pollution around the campus. Various types of plants are believed to absorb carbon and lead $(\mathrm{Pb})$ so as to reduce the impact of pollution. For that reason, it is necessary to do research to find out the plants that effectively absorb lead $(\mathrm{Pb})$ and bind carbon to some plants in Jambi University Campus, Mendalo. This research was conducted for 6 months in Biotechnology and Engineering Laboratory, FST UNJA and Integrated Laboratory of UNPAD Bandung. The method used in this research is survey method to determine the location of the main gate (station I), ATM gate (Station II), rectorate area (Station III), economic faculty area (Station IV), and FST area and forestry (Station V) . The data collected were lead $(\mathrm{Pb})$ and carbon level. The results showed that the plants that are able to absorb the greatest lead $(\mathrm{Pb})$ levels are bintaro while the best carbon absorbent plant is mahogany. The amount of lead and carbon content of the plant is influenced by several factors including the location of sampling, the intensity of the vehicle, the age of the plant leaves, and the type of plant
\end{abstract}

Keywords : Lead, Carbon, University of Jambi

\section{PENDAHULUAN}

Universitas Jambi memiliki beberapa kampus yang terletak di tiga lokasi di Jambi, yaitu di Telanaipura (Unja Telanai), Pasar (Unja Pasar) dan Mendalo (Unja Mendalo). Adapun kampus utama Universitas Jambi berada di daerah Mendalo. Jalan utama menuju kampus tersebut merupakan jalan lintas Sumatera yang dilalui oleh banyak kendaraan berukuran besar, sedang dan kecil. Asap dari kendaraan bermotor tersebut berpengaruh terhadap tingkat polusi udara di sekitar kampus Universitas Jambi. Dampak polusi tersebut tidak hanya manusia, akan tetapi juga tumbuhan yang ada disekitar lingkungan kampus Universitas Jambi. Jamhari (2014) mengemukakan berkaitan dengan pencemaran udara, kendaraan bermotor dikelompokkan sebagai sumber pencemar yang bergerak. Penyebaran bahan pencemar yang diemisikan dari kendaraan bermotor memiliki pola penyebaran spasial yang meluas.

Kampus Universitas Jambi di Mendalo memiliki luas sekitar 100,1 Ha (website unja.ac.id). Sebagian besar di lingkungan kampus banyak ditanami berbagai jenis tumbuhan. Penanaman tersebut selain bertujuan agar kampus menjadi hijau juga diharapkan dapat mengurangi tingkat polusi udara yang ada disekitar kampus. Polusi udara di kampus berasal dari banyaknya kendaraan bermotor yang berada di lingkungan kampus Universitas Jambi. Dahlan (1992) menjelaskan bahwa kendaraan bermotor merupakan sumber utama 
timbal $(\mathrm{Pb})$ yang mencemari udara di daerah perkotaan.

Sumber utama timbal dan karbon di kampus Universitas Jambi berasal dari kendaraan bermotor yang lalu lalang di sepanjang jalan lintas Sumatera. Selain itu, juga berasal dari kendaraan bermotor yang dibawa oleh mahasiswa dan dosen. Permasalahan lain yaitu di kampus Universitas Jambi akan banyak dibangun gedung-gedung baru dibeberapa lokasi. Pembangunan tersebut dalam rangka untuk menunjang kebutuhan saranan dan prasarana mahasiswa. Pembangunan gedung akan mengakibatkan banyak tanaman yang ditebang, baik tanaman peneduh ataupun tanaman lain yang berada disekitarnya. Penebangan tersebut akan berdampak terhadap kualitas udara di lingkungan kampus. Udara kampus menjadi panas dan lingkungan kampus menjadi tidak hijau.

Berbagai upaya perlu dilakukan agar lingkungan kampus tetap menjadi asri, antara lain dengan melakukan penanaman tanaman baru yang mampu menyerap karbon dan gas emisi kendaraan bermotor dengan baik. Akan tetapi, tanaman baru tersebut belum diketahui kemampuannya untuk menyerap emisi. Oleh sebab itu, tanaman yang akan ditanam sebaiknya adalah tanaman yang sudah ditanam dilingkungan kampus tetapi jumlahnya masih terbatas serta kemampuan menyerap emisi kendaraan bermotor dan penyerap karbon telah diketahui.

Salah satu upaya mengurangi kandungan partikel timbal dalam udara adalah menggunakan fungsi ekologis tanaman, dimana tiap-tiap jenis tanaman mempunyai kemampuan yang berbeda-beda dalam menurunkan kandungan timbal dari udara. Fakuara (1990) seperti yang dikutip oleh Edi Rustanto menyatakan bahwa tanaman damar (Agathis alba), mahoni (Swietenia macrophylla), jamuju (Padocarpus imbricatus), pala (Mirystica fragrans), asam landi (Pithecelabium dulce), lahar (Cassia siamea), mempunyai kemampuan sedang-tinggi dalam menurunkan kandungan timbal dari udara.

Berdasarkan latar belakang tersebut, maka dianggap perlu melakukan penelitian penyerapan timbal dan pengikatan karbon pada beberapa tanaman yang paling banyak dan yang ada di lingkungan Universitas Jambi diantaranya glodokan (Polyalthea longifolia), mahoni (Swieenia macrophylla King.), bintaro (Cerbera manghas), dan pulai (Alstonia scholaris).

\section{METODE PENELITIAN}

Penelitian dilaksanakan di lingkungan kampus Universitas Jambi, Laboratorium Bioteknologi dan Rekayasa, Fakultas Sains dan Teknologi Universitas Jambi dan Laboratorium Terpadu Universitas Padjajaran, Bandung dari bulan AprilSeptember 2017 menggunakan metode survey. Sampel diambil pada 5 titik yang berbeda di kampus Universitas Jambi, berdasarkan empat penjuru mata angin ditambah satu pada posisi sentral di wilayah penelitian. Parameter yang diamati adalah kadar timbal dan kadar karbon. Sampel daun berupa tanaman bintaro, glodokan, pulai, sengon, mahoni, pinang merah, dan palem botol, yang terletak pada lapisan tajuk paling bawah dan dari cabang yang dekat pada batang utama, dan yang berwarna hijau tua. Berdasarkan kriteria (1) memiliki tinggi tanaman minimal 2 meter (untuk membatasi agar umur tanaman 
tidak terlalu muda); (2) diameter batang minimal $20 \mathrm{~cm}$; (3) daun yang diambil berwarna hijau tua atau berada di pangkal tajuk (daun berumur tua sehingga diharapkan akumulasi timbal dalam daun sudah lama.

\section{Pengukuran Kadar Timbal (Pb)}

Pengukuran kadar $\mathrm{Pb}$ dila-

kukan dengan mengambil \pm 5 gram sampel daun kemudian dipanaskan dalam oven bersuhu $70^{\circ} \mathrm{C}$ sampai mencapai berat kering yang konstan. Sampel daun hasil pengeringan diabukan dalam furnace bersuhu $600^{\circ} \mathrm{C}$ selama 1 jam. Abu daun diberi $\mathrm{HNO}_{3}$ pekat (65\%) dan akuades masing-masing sebanyak $5 \mathrm{~mL}$, dipanaskan, dan ditambah air sampai tanda batas $25 \mathrm{~mL}$. Larutan tersebut diukur kadar timbalnya dengan AAS (Atomic Absorption Spectrophotometry). Perhitungan kadar timbal daun menurut Istiaroh et al., (2014) menggunakan rumus sebagai berikut :

$$
C y^{\prime}=\frac{w}{c y x v}
$$

Keterangan :

$\mathrm{Cy}^{\prime}=$ kandungan $\mathrm{Pb}$ pada jaringan daun $(\mu \mathrm{g} / \mathrm{g})$

$\mathrm{Cy}=$ konsentrasi $\mathrm{Pb}$ terukur pada AAS $(\mu \mathrm{g} / \mathrm{mL})$

$\mathrm{V}=$ volume pengenceran $(\mathrm{mL})$

$\mathrm{W}$ = berat kering daun $(\mathrm{g})$

\section{Pengukuran Kadar Karbon}

Pengukuran kadar karbon dilakukan dengan menghitung kadar Abu Total (Dry Ashing) menggunakan metode drying ash yang dihitung menggunakan rumus:

$$
\text { AAK }=\frac{\text { Bk Sub Contoh }}{\text { Bb Sub Contoh }} \times \text { Total Bb }
$$

Keterangan :

AAK = Analisis Kadar Karbon

$\mathrm{Bk}=$ berat kering

$\mathrm{Bb}=$ berat basah

\section{HASIL DAN PEMBAHASAN}

Kadar Timbal (Pb)

Pengukuran kadar timbal pada penelitian ini dilakukan dengan AAS (Atomic Absorption Spectrophotometry) (Gambar 1). Dari hasil analisis kadar timbal menggunakan AAS pada empat jenis tanaman di lima stasiun perbedaan kandungan kadar timbal pada setiap daun tersebut menunjukkan kemampuan tanaman sebagai tanaman penyerap timbal. Semakin tinggi kadar timbal yang terukur pada daun, maka semakin baik tanaman tersebut menyerap timbal.

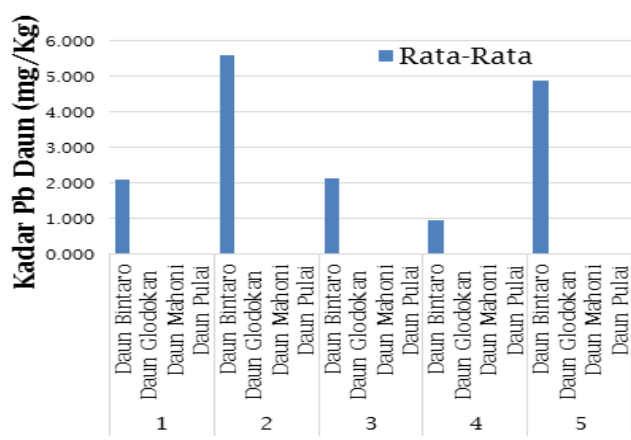

Gambar 1. Kadar TImbal Daun Tanaman Bintaro, Pulai, Mahoni dan Glodokan di Lingkungan Universitas Jambi.

Tinggi rendahnya kadar timbal yang terserap pada daun, kemungkinan disebabkan oleh perbedaan banyaknya kendaraan bermotor yang berlalu-lalang di sekitar lokasi pengambilan sampel. Semakin banyak kendaraan yang berlalu-lalang di sekitar lokasi pengambilan sampel, maka akan semakin banyak timbal yang akan terserap oleh daun pada tanaman

Beberapa tanaman tersebut berada pada tempat yang jarang dilalui oleh kendaraan bermotor dan 
jauh dari jalan utama. Hal ini menunjukkan bahwa tanaman glodokan, tanaman mahoni, tanaman pulai memiliki kemampuan menyerap timbal yang rendah dan kurang baik untuk dijadikan sebagai tanaman penyerap timbal. Akan tetapi, pada beberapa penelitian menunjukkan bahwa tanaman glodokan memiliki kemampuan yang tinggi untuk menyerap timbal beberapa ruas jalan di Purwokerto sebesar 0,977 mg/L (Santoso, S. et al., 2012). Ketidaksesuaian tersebut dimungkinkan oleh faktor fisiologis yang tidak sama antara Purwokerto dan Jambi, sehingga dapat mempengaruhi pertumbuhan tanaman dan berakibat pada kemampuan tanaman tersebut untuk menyerap timbal juga tidak sama.

Organ tanaman yang digunakan pada penelitian ini adalah daun. Bahan pencemar seperti timbal dapat terakumulasi pada tanaman, khususnya di organ daun. Menurut Widagdo (2005) sebagian besar bahanbahan pencemar udara mempengaruhi tanaman melalui daun. Jaringan daun terdiri dari epidermis, mesofil, dan berkas pembuluh. Mekanisme tanaman untuk bertahan dari timbal adalah melalui pergerakan membuka dan menutup stomata dan proses detoksifikasi.

Pada penelitian ini, daun bintaro merupakan salah satu daun yang dapat menyerap timbal dengan baik. Akumulasi timbal pada daun bintaro akan menyebabkan penurunan jumlah stomata. Berdasarkan hasil perhitungan jumlah stomata (Tabel 1), rerata jumlah stomata yang terkecil dimiliki oleh daun bintaro sebesar 361. Tanaman yang hidup disekitar lokasi dengan tingkat pencemaran yang tinggi, akan mengalami penurunan jumlah stomata. Menurut de
Silva et al., (2012), pada tanaman maple merah yang tumbuh di daerah yang tercemar logam berat mengalami penurunan jumlah stomata dan kadar klorofil.

Tabel 1. Jumlah stomata pada masing-masing stasiun di wilayah kampus Universitas Jambi

\begin{tabular}{cccccc}
\hline \multirow{2}{*}{ Daun } & \multicolumn{5}{c}{ STASIUN } \\
\cline { 2 - 6 } & I & II & III & IV & V \\
\hline Mahoni & 63 & 131 & 99 & 64 & 74 \\
Bintaro & 67 & 68 & 80 & 79 & 73 \\
Glodokan & 73 & 113 & 78 & 62 & 65 \\
\hline
\end{tabular}

Daun bintaro juga memiliki permukaan daun yang lebar dan tebal jika dibandingkan dengan ketiga daun tanaman lain yang digunakan. Partikel timbal dari udara akan terserap pada permukaan daun. Helaian daun yang lebar dan berbulu lebih mudah menyerap partikel daripada permukaan daun yang sempit dan tidak berbulu (Flanagan et al., 1980).

\section{Kadar Karbon}

Pengukuran karbon pada daun bertujuan untuk mengetahui laju produktivitas tumbuhan. Banyaknya karbon tersimpan secara teoritik umumnya dijumpai pada batang dalam bentuk lignin, namun pengukuran pada daun dapat menggambarkan keberadaan karbon tersebut karena C pada karbon berbanding lurus dengan $\mathrm{CO}_{2}$ selama fotosistesis berlangsung. Karbondioksida yang telah diabsorbsi oleh daun akan diubah dalam bentuk senyawa organik karbohidrat dan turunannya yang kemudian disimpan didalam batang (Kramer dan Kozlowski, 1979). Hasil pengukuran kadar karbon disajikan pada Tabel 2.

Tabel 2. menunjukkan kadar tertinggi karbon tersimpan ditemukan pada pohon mahoni di lokasi III sebesar $66,00 \mathrm{~g} / \mathrm{m}^{2}$. Data jumlah karbon tersebut juga didukung oleh 
tingginya indeks stomata pada lokasi tersebut yaitu sebesar 99 pada pohon yang sama. Peningkatan jumlah stomata sebanding dengan jumlah kadar karbon yang diserap karena $\mathrm{CO}_{2}$ masuk kedalam tumbuhan melalui stomata (June, 2006). Hasil uji klorofil juga menjelaskan bahwa pada pohon yang sama di lokasi yang sama jumlah klorofilnya sebesar 3,80 mg/g. Nilai ini merupakan nilai yang tergolong tinggi bila dilihat dari hasil uji klorofil tertinggi untuk seluruh lokasi penelitian yaitu sebesar 5,14 yang ditemukan pada mahoni di lokasi I.

Tabel 2. Hasil Pengukuran Kadar Karbon

\begin{tabular}{|c|c|c|c|c|c|}
\hline$\underset{\Xi}{\Xi}$ & $\begin{array}{l}\text { Nama } \\
\text { Spesies }\end{array}$ & $\begin{array}{l}\text { Berat } \\
\text { Basah }\end{array}$ & $\begin{array}{c}\text { Berat } \\
\text { Kering }\end{array}$ & $\begin{array}{l}\text { Berat } \\
\text { Total }\end{array}$ & $\begin{array}{l}\text { Kadar } \\
\text { Karbon } \\
(\mathrm{g} / \mathrm{m} 2)\end{array}$ \\
\hline \multirow{4}{*}{ 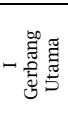 } & Bintaro & 30 & 9,6 & 99 & 31,68 \\
\hline & Pulai & 30 & 19,6 & 90 & 58,80 \\
\hline & Glodokan & 25 & 18,1 & 60 & 43,44 \\
\hline & Mahoni & 30 & 16,6 & 100 & 55,33 \\
\hline \multirow{4}{*}{ 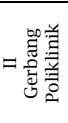 } & Bintaro & 30 & 9,3 & 65 & 20,15 \\
\hline & Pulai & 20 & 14,8 & 60 & 44,40 \\
\hline & Glodokan & 20 & 17,7 & 60 & 53,10 \\
\hline & Mahoni & 30 & 19,4 & 90 & 58,20 \\
\hline \multirow{4}{*}{$\equiv \frac{\stackrel{\vec{\sigma}}{\frac{\vec{b}}{0}}}{\approx}$} & Bintaro & 30 & 9,3 & 100 & 31,00 \\
\hline & Pulai & 30 & 17,3 & 70 & 40,37 \\
\hline & Glodokan & 30 & 21,3 & 80 & 56,80 \\
\hline & Mahoni & 30 & 19,8 & 100 & 66,00 \\
\hline \multirow{4}{*}{$\geq \frac{\text { 咅 }}{\text { 至 }}$} & Bintaro & 30 & 10,9 & 100 & 36,33 \\
\hline & Pulai & 30 & 14,4 & 50 & 24,00 \\
\hline & Glodokan & 30 & 18 & 100 & 60,00 \\
\hline & Mahoni & 20 & 15,4 & 50 & 38,50 \\
\hline \multirow{4}{*}{$>\vec{s}$} & Bintaro & 30 & 9,6 & 75 & 24,00 \\
\hline & Pulai & 30 & 14,3 & 100 & 47,67 \\
\hline & Glodokan & 30 & 18,7 & 75 & 46,75 \\
\hline & Mahoni & 30 & 23,6 & 60 & 47,20 \\
\hline
\end{tabular}

Lokasi III area penelitian merupakan area gedung rektorat dan berada tepat ditengah-tengah kampus UNJA, sehingga lalu-lalang kendaraan yang keluar masuk UNJA akan melalui area tersebut. Banyaknya emisi yang dikeluarkan oleh kendaraan bermotor, meningkatkan kadar $\mathrm{CO}_{2}$ di udara, sehingga menyebabkan terbukanya stomata. Penelitian Hidayati (2013) menunjukkan bahwa terdapat korelasi antara pembukaan stomata dengan besarnya serapan $\mathrm{CO}_{2}$. Lokasi lain yang mempunyai nilai tertinggi adalah lokasi IV (Fakultas Hukum) dan lokasi I (gerbang utama).

Pengukuran jumlah $\mathrm{CO}_{2}$ pada lokasi IV menunjukkan angka $60 \mathrm{~g} / \mathrm{m}^{2}$ terdapat pada pohon glodokan. Lokasi ini merupakan jalur keluar kendaraan dari kampus UNJA dan jalur kendaraan menuju Masjid UNJA sehingga lokasi ini juga merupakan lokasi yang terpapar emisi $\mathrm{CO}_{2}$. Glodokan merupakan tanaman yang kerap dijadikan sebagai tanaman peneduh pinggir jalan dan sekaligus merupakan penyerap $\mathrm{CO}_{2}$ yang baik. Penelitian Hidayati (2013) tentang serapan karbon dioksida di Ecopark Cibinong Bogor menunjukkan bahwa nilai serapan pohon ini tergolong sedang yaitu sebesar $5,69 \mu \mathrm{mol} / \mathrm{m}^{2} / \mathrm{s}$.

Demikian juga bila dilihat pada lokasi I yang merupakan jalur masuk dan jalur keluar kampus UNJA. Jalur ini tidak hanya dipengaruhi oleh kendaraan yang masuk dan keluar tetapi dipengaruhi oleh jalan raya Jambi-Muara Bulian sehingga menambah banyak emisi $\mathrm{CO}_{2}$. Hasil uji kadar karbon pada lokasi I menunjukkan bahwa kadar karbon tertinggi terdapat pada pohon pulai yaitu sebesar 58,80 $\mathrm{g} / \mathrm{m}^{2}$. Pohon ini merupakan jenis terbanyak dilokasi I dengan diameter mencapai $30 \mathrm{~cm}$. Tingginya serapan $\mathrm{CO}_{2}$ oleh pohon pulai di lokasi ini disebabkan karena pohon tersebut memiliki umur yang sudah tua dan memiliki tajuk yang lebar. Pohonpohon yang sudah tua memiliki klorofil yang lebih banyak dan lebih efektif berfotosintesis dibanding dengan daun yang masih muda (Hidayati, 2013). Penelitian Nursanti (2013) di Kampus UNJA Mendalo menunjukkan bahwa pohon pulai dan pohon mahoni merupakan pohonpohon yang memiliki Indeks Nilai Penting di Kampus Unja Mendalo. 
Kadar serapan $\mathrm{CO}_{2}$ terendah teramati pada lokasi II (Ruas Jalan Poliklinik Unja) sebesar 20,15 g/m² terdapat pada pohon bintaro. Rendahnya nilai ini disebabkan karena ruas jalan ini dinon-aktifkan sehingga jarang sekali kendaraan melalui ruas jalan ini. Secara geografis jalan ini memang berdekatan dengan jalan raya, namun vegetasi utama yang berada pada jalur terdepan adalah mahoni sehingga pada lokasi ini kadar tertinggi serapan $\mathrm{CO}_{2}$ ditemukan pada mahoni yaitu sebesar 58,20 $\mathrm{g} / \mathrm{m}^{2}$. Bintaro yang ditemukan pada lokasi ini relatif masih muda sehingga laju serapannya kalah dibandingkan dengan pohon mahoni dan pohon lain yang berada di lokasi ini. Penelitian Ihsan (2016) menyebutkan bahwa jumlah individu bintaro di Kampus UNJA Mendalo sebesar 14,84\% dari total pohon utama, yang tersebar di seluruh areal kampus. Jumlah individu yang besar tersebut tidak menjamin besarnya serapan $\mathrm{CO}_{2}$ yang dapat diserap. Rendahnya indeks stomata pada pohon ini pada lokasi II juga

\section{DAFTAR PUSTAKA}

Dahlan, E.N. 1992. Hutan Kota Untuk Pengelolaan dan Peningkatan Kualitas Lingkungan Hidup. PT Enka Parahiyangan, Jakarta.

De Silva, N.D.G., Cholewa, E., Ryser, P. 2012. Effects of Combinet Drought and Heavy Metal Stresses on Xylem Structure and Hydraulic Conductivity in Red Maple (Acer rubrum L.). Journal of Experimental Botany, doi: 10.1093/jxb/ers241. 1-10.

Flanagan, J. T., K. J. Wade, A. Curie, D. J. Curtis. 1980. The Deposition of Lead and Zinc from Traffic Pollution on Two Roadside menjadi penyebab rendahnya serapan $\mathrm{CO}_{2}$. Lubis (2013), melalui hasil penelitiannya menganalisa bahwa pada bintaro di Jakarta cadangan karbon tersimpannya adalah sebesar 0,1 ton/ha. Hasil ini lebih kecil bila dibandingkan dengan mahoni yaitu sebesar 0,4 ton/ha.

\section{KESIMPULAN}

Berdasarkan hasil penelitian dapat disimpulkan bahwa tanaman bintaro merupakan tanaman dengan kemampuan penyerapan timbal terbanyak, sedangkan tanaman yang mampu menyimpan kadar karbon terbanyak adalah tanaman mahoni. Polusi udara mempengaruhi jumlah stomata, kadar timbal, kadar klorofil, dan kadar karbon. Semakin banyak stomata maka kadar timbal dan kadar karbon semakin sedikit serta kadar klorofil semakin meningkat. Jenis tanaman yang paling baik dalam menyerap timbal $(\mathrm{Pb})$ dan karbon (bintaro dan mahoni) dapat dijadikan sebagai tanaman peneduh di lingkungan kampus Universitas Jambi.

Shrubs. Environment. Pollut. (Series B) (1): 71-78.

Hidayati, N., Mansur, M., Juhaeti, T. 2013. Variasi Serapan Karbondioksida $\left(\mathrm{CO}_{2}\right)$ JenisJenis Pohon di "Ecopark", Cibinong dan Kaitannya dengan Potensi Mitigasi Gas Rumah Kaca. Buletin Kebun Raya. Vol. 16 No. 1 http//www.ut.ac.id/olsupp/FMIPA/LING1112/ kestanah.html, 2001

Ihsan, M., Setiawan, A., Al Rasyid, M.A. 2016. Analisis Kemampuan Pohon dalam Mereduksi $\mathrm{CO}_{2}$ dari Kendaraan Bermotor di 
Kampus Universitas Jambi. Prosiding Semirata.

Istiaroh, P. D., N.K.T. Martuti, F.P.M.H. Bodijanto. $2014 . \quad$ Uji Kandungan Timbal $(\mathrm{Pb})$ dalam Daun Tanaman Peneduh di Jalan Protokol Kota Semarang. Journal of Biology \& Biology Education, 6 (1).

Jamhari, M., 2014. Hubungan Kandungan Timbal $(\mathrm{Pb})$ di Udara dengan $\mathrm{Pb}$ dalam Talus Lichen Xanthoparmelia

xanthofarinosa. Seminar Nasional Biologi VIII Pendidikan Biologi. Biologi, Sains Lingkungan, dan Pembelajaran Menuju Pembangunan Karakter

June, T. 2006. Kenaikan $\mathrm{CO}_{2}$ dan Perubahan Iklim : Implikasinya Terhadap Pertumbuhan Tanaman.http://www.members.trip od.com

Kramer, P.J., Kozlowski, T.T. 1979. Physiology of Woody Plants. Acad Press. New York.

Lubis, S.H., Arifin, H.S., Samsoedin, I. 2013. Analisis Cadangan Karbon Pohon pada Lanskap Hutan Kota di DKI Jakarta. Jurnal Penelitian Sosial dan Ekonomi Kehutanan Vol. 10 (1)

Nursanti, Swari, E.I. 2013. Potensi Keanekaragaman Hayati, Iklim Mikro dan Serapan Karbon Pada Ruang Terbuka Hijau Kampus Mendalo Universitas Jambi.

Sanra, Y., T. Abu H., Subardi, B. 2015. Analisis Kandungan Logam Timbal pada Tanaman Tomat (Solanum lycopersicum L.) yang Ditanam di Pinggir Jalan Raya Kecamatan Aur Birugo Tigo Baleh Bukittinggi. JOM FMIPA. Vol (2) : 1.

Santoso, S., S. Lestari., S. Samiyarsih. 2012. Inventarisasi Tanaman Peneduh Jalan Penyerap Timbal di Purwokerto. Prosiding
Seminar Nasional Pengembangan Sumber Daya Pedesaan dan Kearifan Lokal Berkelanjutan. 197-203. 